\title{
Diagnóstico microbiológico e índice de adição de água do leite cru comercializado no município de Pombal, Paraíba
}

\section{Microbiological diagnosis and water addition index of raw milk marketed in the city of Pombal, Paraíba, Brazil}

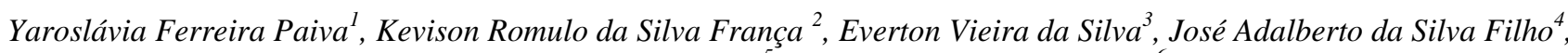 \\ Karla Elita Viegas Pereira ${ }^{5}$, Alfredina dos Santos Araújo ${ }^{6}$
}

Resumo: A comercialização do leite sem tratamento térmico ou controle de inspeção sanitária é proibida por lei em todo o país, mas persiste principalmente em regiões interioranas. Assim, torna-se importante avaliar o leite nestas localidades, como forma de monitoramento do produto que será consumido pela população. Dessa forma, objetivou-se avaliar o diagnóstico microbiológico e o índice de adição de água em amostras de leite cru comercializado no município de Pombal, Paraíba. Foram coletadas três amostras de cada um dos cinco locais de comercialização, entre os meses de maio e junho de 2017. As mesmas foram obtidas em recipientes estéreis e avaliadas quanto aos parâmetros de Coliformes à $45^{\circ} \mathrm{C}(\mathrm{NMP} / \mathrm{mL})$, $\mathrm{presença/ausência}$ de Salmonella sp. e Escherichia coli, Staphylococcus spp. (UFC/mL) e Contagem total de bactérias Aeróbias Mesófilas (CTM) (UFC/mL). O índice de adição de água foi determinado através do equipamento Analisador de leite Master Classic. Todas as amostras apresentaram Coliformes à $45^{\circ} \mathrm{C}(>110 \mathrm{NMP} / \mathrm{mL})$, presença de Salmonella sp. e E. coli, além de altas contagens de Staphylococcus spp. $\left(3,13 \times 10^{2}\right.$ a $\left.2,65 \times 10^{5} \mathrm{UFC} / \mathrm{mL}\right)$ e CTM $\left(2,30 \times 10^{4}\right.$ a $\left.3,91 \times 10^{5} \mathrm{UFC} / \mathrm{mL}\right)$. Observou-se amostras que apresentaram um índice de adição de água de aproximadamente 5\%. O leite cru comercializado no município de Pombal mostrou-se fora dos padrões microbiológicos para todos os parâmetros analisados, além da existência de fraude em amostras pela adição de água, estando impróprio para o consumo.

Palavras-chave: Qualidade; Adulteração; Leite informal; Segurança alimentar.

\begin{abstract}
The commercialization of milk without heat treatment or sanitary inspection control is prohibited by law in all over the country, but it happens in some small cities. It is important to evaluate the milk in these localities, as it will be consumed by the population. The objective of this study was to evaluate the microbiological diagnosis and the index of water addition in samples of raw milk commercialized in the city of Pombal (PB). Three samples were collected from each of the five commercial sites (A, B, C, D and E) between May and June 2017. They were obtained in sterile containers and evaluated for Coliform parameters at $45^{\circ} \mathrm{C}(\mathrm{NMP} / \mathrm{mL})$, presence / absence of Salmonella sp. and Escherichia coli, Staphylococcus spp. (UFC/mL) and total count of Mesophyll Aerobic bacteria (CTM) (UFC/mL). The addition rate of water was determined using the Master Classic Milk Analyzer. All samples presented Coliforms at $45^{\circ} \mathrm{C}$ (>110 NMP / mL), presence of Salmonella sp. And Escherichia coli, In addition to high counts of Staphylococcus spp. (3.13 x 102 at 2.65 x 105 UFC / mL) and CTM (2.30 x 104 at $3.91 \times 105 \mathrm{CFU} / \mathrm{mL}$ ). Samples from locality B had a water addition index of approximately 5\%. We concluded that the raw milk marketed in the city of Pombal (PB) during the period of the research was out of the microbiological standards for all analyzed parameters, besides the existence of fraud by addition of water in the samples of the locality B, being improper for consummation.
\end{abstract}

Key words: Quality; Adulteration; Informal milk; Food security.

\footnotetext{
*Autor para correspondência

Recebido para publicação em 11/11/2017; aprovado em 20/12/2017

${ }^{1}$ Mestranda em Sistemas Agroindustriais, Universidade Federal de Campina Grande, Pombal, Paraíba; yaroslaviapaiva@gmail.com.

${ }^{2}$ Mestrando em Sistemas Agroindustriais, Universidade Federal de Campina Grande, Pombal, Paraíba; kevsfranca@ gmail.com.

${ }^{3}$ Doutor em Química, Universidade Federal de Campina Grande, Pombal, Paraíba; evertonquimica@ gmail.com

${ }^{4}$ Mestrando em Engenharia Ambiental, Universidade Federal Rural de Pernambuco, Recife, Pernambuco; adalbertosilva15@ gmail.com

${ }^{5}$ Mestranda em Sistemas Agroindustriais, Universidade Federal de Campina Grande, Pombal, Paraíba; karla-viegas@ hotmail.com

${ }^{6}$ Professora Doutora, Universidade Federal de Campina Grande, Pombal, Paraíba, alfredina@ @cta.ufcg.edu.br.
} 


\section{INTRODUÇÃO}

Devido ao seu alto teor nutricional, o leite é considerado um dos alimentos mais completos para a saúde humana (SILVA et al., 2008). Esse benefício representa também uma fonte de preocupação por parte dos consumidores e pela indústria de alimentos, uma vez que vários grupos de microrganismos encontram nesta bebida, nutrientes necessários para o seu desenvolvimento (ZOCCHE et al., 2002; SILVA et al., 2008; AMARAL; SANTOS, 2011).

Entre os microrganismos contaminantes do leite destacam-se aqueles responsáveis por alterações físicoquímicas, como aumento da acidez e produção de enzimas que comprometem a qualidade do produto; e os patogênicos que são associados às toxinfecções (MORAES et al., 2005). É por esta razão que a preocupação acerca da qualidade do produto envolve tanto aspectos nutricionais, uma vez que é fonte de alimento (AMARAL; SANTOS, 2011), quanto a aspectos relacionados às doenças transmissíveis por alimentos que em sua maioria são associadas ao consumo de produtos contaminados por microrganismos patogênicos, presentes em carnes, leite e seus derivados (OLIVEIRA et al., 2010).

A obtenção de leite de qualidade envolve uma série de fatores, principalmente aqueles de caráter higiênico-sanitário dos quais destacam-se: a sanidade do rebanho leiteiro e dos ordenhadores (ZENI et al., 2013), higiene local, limpeza e desinfecção diária dos equipamentos utilizados na ordenha, e também a qualidade da água utilizada na propriedade (RAMIRES; BERGER; ALMEIDA, 2009; LUZ et al., 2011). Este último tem influência direta sobre todos os fatores citados, além de contribuir para índices elevados de contagem bacteriana e para o aumento da contaminação do leite por microrganismos deteriorantes e patogênicos (CERQUEIRA et al., 2006).

Além da contaminação do leite descrita, outro importante problema associado a qualidade final do produto são as diversas fraudes durante o processamento, que além de acarretar prejuízos econômicos, podem também oferecer riscos à saúde do consumidor (SILVA et al., 2008; MAREZE, 2015). De acordo com a legislação brasileira, considera-se como fraudado o leite que: 1) for adicionado água; 2) tiver sofrido qualquer subtração dos seus componentes; 3 ) for adicionado substâncias não permitidas; 4) for de um tipo e apresentar-se rotulado como de outra categoria superior; 5) estiver cru e for vendido como pasteurizado; 6) for exposto ao consumo sem garantias de inviolabilidade (BRASIL, 1952).

A adição de água é uma das fraudes mais ocorrentes, e é feita com o objetivo de aumentar o volume do leite produzido, visando uma quantidade maior de lucro, e essa adição geralmente vem acompanhada de substâncias adicionais para mascarar a diluição, como açúcar e sal, por exemplo (PINHEIRO, 2015). Além de aumentar o volume do produto, as fraudes são realizadas também com o objetivo de controlar alterações provocadas por microrganismos (MAREZE et al., 2015), bem como mascarar outros parâmetros físico-químicos perdidos (AMARAL; SANTOS, 2011).

Diversas pesquisas científicas têm sido realizadas com o objetivo de avaliar a qualidade do leite cru comercializado diretamente para população (MENDES et al., 2010; BARBOSA et al., 2014; SILVEIRA; BERTAGNOLLI, 2014; VIEIRA et al., 2014). Essa avaliação é realizada geralmente através de análises microbiológicas e físico-químicas que são capazes de fornecer informações acerca das condições higiênico-sanitárias sob as quais o leite foi produzido e armazenado, além de detectar possíveis fraudes, como adição de água ou desnate, por exemplo (ZOCCHE et al., 2002; LUZ et al., 2011).

A comercialização direta sem tratamento térmico ou controle de inspeção sanitária é proibida por lei em todo o território nacional (BRASIL, 1969), mas persiste principalmente em regiões interioranas devido a fatores como comodidade e baixo custo (AMARAL; SANTOS, 2011). Desta forma, torna-se importante avaliar a qualidade do leite nestas localidades, principalmente como forma de monitoramento para assegurar a qualidade do produto que será consumido pela população.

O "leite informal" comercializado no município de Pombal (PB) é transportado do produtor para os estabelecimentos em latões por motocicletas ou caminhonetes. A distribuição é diária e o produto é vendido a granel diretamente ao consumidor. Sendo assim, o presente estudo foi realizado com o objetivo de avaliar o diagnóstico microbiológico e o índice de adição de água em amostras de leite cru comercializado no município de Pombal, no Alto Sertão paraibano.

\section{MATERIAL E MÉTODOS}

Trata-se de um estudo experimental com abordagem quantitativa realizada a partir do leite cru comercializado no município de Pombal-PB. Inicialmente foi realizada uma pesquisa informativa acerca da comercialização deste tipo de produto no município e a partir disso, foram identificados os pontos de venda, sendo selecionados cinco deles, considerando os com atividade comercial mais intensa, que foram identificados como: A, B C D e E.

As amostras foram coletadas entre os meses de maio a junho de 2017, durante 3 semanas consecutivas nas 5 localidades (totalizando 15 amostras). As mesmas foram obtidas em recipientes estéreis, posteriormente acondicionadas em caixa isotérmica e encaminhadas sob refrigeração dentro do prazo máximo de 30 minutos para o Laboratório de Microbiologia de Alimentos (LMA), do Centro de Ciências e Tecnologia Agroalimentar (CCTA), da Universidade Federal de Campina Grande (UFCG).

As amostras foram analisadas quanto aos parâmetros de coliformes à $45^{\circ} \mathrm{C} \quad(\mathrm{NMP} / \mathrm{mL})$, Salmonella $\mathrm{sp}$. (presença/ausência), Staphylococcus spp. (UFC/mL), Contagem total de bactérias Aeróbias Mesófilas (CTM) (UFC/mL) e Escherichia coli. (presença/ausência). Todas as análises foram realizadas com base na metodologia adotada por Silva et al (2010)

O índice de adição de água foi determinado através do equipamento Analisador de leite Master Classic.

\section{RESULTADOS E DISCUSSÃO}

Devido à inexistência de legislação específica para leite cru, os resultados foram comparados com a IN62 (BRASIL, 2011) com valores para leite cru refrigerado.

Os resultados para Coliformes à $45^{\circ} \mathrm{C}(\mathrm{NMP} / \mathrm{mL})$ estão dispostos na Tabela 1. 
Tabela 1. Coliformes à $45^{\circ} \mathrm{C}(\mathrm{NMP} / \mathrm{mL})$ em amostras de leite cru comercializadas no município de Pombal, Paraíba entre maio e junho de 2017.

\begin{tabular}{cccc}
\hline Locais de comercialização & $1^{\circ}$ Semana & $2^{\circ}$ Semana & $3^{\circ}$ Semana \\
\hline A & $>110 \mathrm{NMP} / \mathrm{mL}$ & $>110 \mathrm{NMP} / \mathrm{mL}$ & $>110 \mathrm{NMP} / \mathrm{mL}$ \\
B & $>110 \mathrm{NMP} / \mathrm{mL}$ & $>110 \mathrm{NMP} / \mathrm{mL}$ & $>110 \mathrm{NMP} / \mathrm{mL}$ \\
C & $>110 \mathrm{NMP} / \mathrm{mL}$ & $>110 \mathrm{NMP} / \mathrm{mL}$ & $>110 \mathrm{NMP} / \mathrm{mL}$ \\
D & $>110 \mathrm{NMP} / \mathrm{mL}$ & $>110 \mathrm{NMP} / \mathrm{mL}$ & $>110 \mathrm{NMP} / \mathrm{mL}$ \\
E & $>110 \mathrm{NMP} / \mathrm{mL}$ & $>110 \mathrm{NMP} / \mathrm{mL}$ & $>110 \mathrm{NMP} / \mathrm{mL}$ \\
\hline
\end{tabular}

Todas as amostras analisadas apresentaram coliformes à $45^{\circ} \mathrm{C}>110 \mathrm{NMP} / \mathrm{mL}$ durante as três semanas de coleta, estando acima do limite determinado pela legislação vigente que é de 4,0 NMP/mL.

Amaral e Santos (2011) avaliando leite cru comercializado na cidade de Solânea (PB) encontrou valores acima do padrão para coliformes à $45^{\circ} \mathrm{C}$ entre $1,1 \times 10^{4} \mathrm{e}>2,4$ $\mathrm{x} 10^{4} \mathrm{NMP} / \mathrm{mL}$. Das amostras de leite cru do estado da Paraíba analisadas por Freitas, Travassos e Maciel (2013), $78 \%$ delas também estiveram acima do padrão, demonstrando que a contaminação por esse grupo de microrganismos também afeta outras cidades do Estado. O mesmo ocorreu com $100 \%$ das amostras de leite cru analisadas por Luz et al. (2011) advindas da região do Alto Pantanal Sul-MatoGrossense.

Segundo Quintana e Carneiro (2006) a presença destes microrganismos sugere higiene insatisfatória durante o processo de ordenha, armazenamento e/ou transporte do leite, uma vez que os coliformes são considerados indicadores de contaminação do ambiente e resíduos fecais.
A presença de Escherichia coli foi encontrada em amostras de todos os locais de comercialização, estando assim impróprias para consumo. Sequetto et al. (2017) analisaram amostras de leite cru de propriedades rurais de MG e concluíram que $60 \%$ continham a presença de Escherichia coli.

Menezes et al. (2015) destacam que as fontes mais comuns de contaminação por esse grupo de bactérias são fezes de animais e resíduos do solo que podem contaminar o leite por meio da água utilizada na produção e higienização de superfícies, utensílios e equipamentos contaminados.

Para a presença de Staphylococcus spp., a contagem média em leite cru permitida para este microrganismo também é de $1 \times 10^{5} \mathrm{UFC} / \mathrm{mL}$, sendo que essa quantidade do microrganismo presente por grama ou mililitro de alimento constitui riscos de produção de enterotoxinas estafilocócicas, podendo provocar um quadro de intoxicação alimentar (BERGDOLL, 1989) representando assim um risco a saúde pública. Os valores obtidos para a contagem de Staphylococcus spp. no presente estudo, estão descritas na Tabela 2.

Tabela 2. Staphylococcus spp. (UFC/mL) em amostras de leite cru comercializadas no município de Pombal, Paraíba entre maio e junho de 2017.

\begin{tabular}{cccc}
\hline Locais de comercialização & $1^{\circ}$ Semana & $2^{\circ} \mathrm{Semana}$ & $3^{\circ} \mathrm{Semana}$ \\
\hline A & $3,13 \times 10^{2} \mathrm{UFC} / \mathrm{mL}$ & $1,50 \times 10^{2} \mathrm{UFC} / \mathrm{mL}$ & $4,00 \times 10^{2} \mathrm{UFC} / \mathrm{mL}$ \\
B & $1,97 \times 10^{4} \mathrm{UFC} / \mathrm{mL}$ & $1,31 \times 10^{2} \mathrm{UFC} / \mathrm{mL}$ & $3,89 \times 10^{4} \mathrm{UFC} / \mathrm{mL}$ \\
C & $8,52 \times 10^{3} \mathrm{UFC} / \mathrm{mL}$ & $2,15 \times 10^{2} \mathrm{UFC} / \mathrm{mL}$ & $1,60 \times 10^{4} \mathrm{UFC} / \mathrm{mL}$ \\
D & $1,46 \times 10^{5} \mathrm{UFC} / \mathrm{mL}$ & $2,67 \times 10^{4} \mathrm{UFC} / \mathrm{mL}$ & $2,65 \times 10^{5} \mathrm{UFC} / \mathrm{mL}$ \\
E & $8,76 \times 10^{4} \mathrm{UFC} / \mathrm{mL}$ & $4,63 \times 10^{2} \mathrm{UFC} / \mathrm{mL}$ & $1,57 \times 10^{5} \mathrm{UFC} / \mathrm{mL}$ \\
\hline
\end{tabular}

Os valores obtidos a partir da contagem de Staphylococcus spp. indicam que todas as amostras obtidas nas localidades A, B e C encontraram-se dentro do padrão determinados pela legislação vigente para este parâmetro. Por outro lado, 20\% das amostras (correspondentes às localidades D e E) apresentaram-se fora do padrão estabelecido, com contagem variando de $1,46 \times 10^{5}$ a $2,65 \times 10^{5} \mathrm{UFC} / \mathrm{mL}$. Lamaita et al. (2005) ao realizarem a contagem desse microrganismo a partir de amostras de leite em propriedades rurais do estado de MG, observaram o crescimento em $100 \%$ das amostras, com contagem variando de $1 \times 10^{5}$ a $2,5 \times 10^{7} \mathrm{UFC} / \mathrm{mL}$, variação essa explicada pela diversificação nos sistemas de produção o que leva a maior ou menor contaminação devido a mastite e/ou a contaminação por ordenhadores portadores assintomáticos desses microrganismos.

A presença desse microrganismo no leite era esperada, uma vez que espécies do gênero estão presentes de forma assintomática no rebanho e durante a ordenha pode ter ocorrido a contaminação cruzada a partir dos ordenhadores, levando em consideração que no ser humano, esse microrganismo está presente em diversas partes do corpo, como pele, garganta e fossas nasais também de forma assintomática (SANTOS et al., 2007), além disso podem ser disseminados através do contato direto do seu portador com outras superfícies (GOEL; GOEL, 2009).

A Contagem total de bactérias aeróbias mesófilas (CTM) variou de $2 \times 10^{4}$ a $3,9 \times 10^{5} \mathrm{UFC} / \mathrm{mL}$ como observa-se na Tabela 3.

Das amostras analisadas, 53,3\% apresentaram valores de contagem acima do determinado pela legislação, que é $1 \times 10^{5} \mathrm{UFC} / \mathrm{mL}$. Com exceção da localidade $\mathrm{A}$, todas as demais apresentaram ao menos uma amostra fora deste padrão. Observa-se ainda que na localidade $\mathrm{D}$, todas as amostras coletadas semanalmente apresentaram valores altos de contagem. Amaral e Santos (2011) avaliaram a qualidade do leite cru informal no município de Solânea-PB e observaram que todas as amostras analisadas apresentaram contagem de bactérias mesófilas acima do determinado pela legislação. Mattos et al. (2010), em um estudo de mesma natureza, avaliaram a qualidade do leite cru produzido na região do agreste pernambucano e como resultado para CTM, $83 \%$ das amostras avaliadas encontraram-se acima do valor estabelecido pela legislação. 
Tabela 3 Contagem total de bactérias aeróbias mesófilas (UFC/mL) em amostras de leite cru comercializadas no município de Pombal, Paraíba entre maio e junho de 2017.

\begin{tabular}{cccc}
\hline Locais de comercialização & $1^{\circ}$ Semana & $2^{\circ}$ Semana & $3^{\circ}$ Semana \\
\hline A & $5,11 \times 10^{4} \mathrm{UFC} / \mathrm{mL}$ & $3,95 \times 10^{4} \mathrm{UFC} / \mathrm{mL}$ & $4,69 \times 10^{4} \mathrm{UFC} / \mathrm{mL}$ \\
B & $2,94 \times 10^{5} \mathrm{UFC} / \mathrm{mL}$ & $7,58 \times 10^{4} \mathrm{UFC} / \mathrm{mL}$ & $1,72 \times 10^{5} \mathrm{UFC} / \mathrm{mL}$ \\
C & $1,19 \times 10^{5} \mathrm{UFC} / \mathrm{mL}$ & $5,85 \times 10^{4} \mathrm{UFC} / \mathrm{mL}$ & $6,52 \times 10^{4} \mathrm{UFC} / \mathrm{mL}$ \\
D & $1,15 \times 10^{5} \mathrm{UFC} / \mathrm{mL}$ & $3,21 \times 10^{5} \mathrm{UFC} / \mathrm{mL}$ & $3,91 \times 10^{5} \mathrm{UFC} / \mathrm{mL}$ \\
E & $2,78 \times 10^{5} \mathrm{UFC} / \mathrm{mL}$ & $2,30 \times 10^{4} \mathrm{UFC} / \mathrm{mL}$ & $1,54 \times 10^{5} \mathrm{UFC} / \mathrm{mL}$ \\
\hline
\end{tabular}

De acordo com Luz et al. (2011), valores altos de contagem bacteriana indicam problemas de assepsia no momento da ordenha, principalmente por parte da higiene do ordenhador e dos utensílios utilizados. Beloti et al. (2011) reiteram e afirmam que o alto índice de contagem indica também falta de higiene durante $\mathrm{o}$ armazenamento do produto. A contagem de bactérias mesófilas aeróbias é um parâmetro microbiológico de extrema importância, uma vez que este grupo de microrganismo é composto principalmente por bactérias de importância médica por serem patogênicas ao homem.

Foi isolada Salmonella sp. em todas as amostras avaliadas e por esta razão as mesmas encontram-se fora do padrão estabelecido pela legislação (RDC nº12) (BRASIL, 2001), que determina a ausência do microrganismo a cada $25 \mathrm{~mL}$ do produto. Resultados opostos a este foram obtidos por Amaral e Santos (2011) e Mattos (2010), em que todas as amostras de leite cru avaliadas foram negativas para a presença de Salmonella sp. Freitas, Travassos e Maciel (2013), em um estudo de mesma natureza, realizaram avaliação do leite cru produzido em três regiões do estado da Paraíba e obtiveram amostras com colônias características do gênero, porém a presença de Salmonella sp. não foi confirmada pelos autores. Por ser capaz também de provocar toxinfecções, a presença deste microrganismo classifica o produto como impróprio para consumo em sua condição in natura (FREITAS; TRAVASSOS; MACIEL, 2013).

A ausência de controle higiênico sanitário do rebanho, a falta de higiene dos ordenhadores no momento da obtenção do produto e o transporte inadequado desde o ponto de origem até os estabelecimentos de venda, sem nenhum tipo de refrigeração são fatores que contribuem para a má qualidade microbiológica do leite.

Com relação ao índice de adição de água, o equipamento analisador utilizado para essa análise determinou que houve $4,7 \%$ de adição de água nas amostras da localidade B. A fraude pode ser confirmada pelo elevado índice crioscópico apresentado pelas amostras desta localidade, com valor de $-0.474^{\circ} \mathrm{H}$, estando acima do estabelecido pela legislação que determina a faixa entre $0,530^{\circ} \mathrm{H}$ a $-0,550^{\circ} \mathrm{H}$ (equivalentes a $-0,512^{\circ} \mathrm{C}$ a $-0,531^{\circ} \mathrm{C}$ ) como aceitável para esse parâmetro (BRASIL, 2011). Nas demais localidades não houveram indícios desse tipo de fraude. Amaral e Santos (2011) avaliaram a qualidade físicoquímica do leite cru informal em três localidades no município de Solânea-PB e evidenciaram fraude por adição de água em amostras provenientes de duas destas localidades. Beloti et al. (2011) ao avaliarem a qualidade físico-química do leite cru produzido em Sapopema-PR submeteram 160 amostras à análise de índice crioscópico e observaram que destas, $29(18,12 \%)$ apresentaram valores acima do padrão determinado pela legislação, levando a conclusão de que houve a adição de água.

\section{CONCLUSÕES}

O leite cru comercializado no município de Pombal no período da pesquisa mostrou-se fora dos padrões microbiológicos para todos os parâmetros analisados, estando impróprio para o consumo. Além de fraude em amostra por adição de água.

Esses dados reforçam a precariedade no formato de produção, existindo assim a necessidade de adoção das boas práticas de fabricação e boas práticas de ordenha, além de uma maior fiscalização dos órgãos competentes.

\section{REFERÊNCIAS}

AMARAL, C. R. S.; SANTOS, E. P. Leite cru comercializado na cidade de Solânea, PB: caracterização físico-química e microbiológica. Revista Brasileira de Produtos Agroindustriais, Campina Grande, v.13, n.1, p.7-13, 2011.

BARBOSA, H. P.; LIMA, C. U. G. B.; SANTANA, A. M. F. LINS, A. A.; POLIZELli, M.; MARTINS, P. S. Caracterização físico-química de amostras de leite in natura comercializados no estado da Paraíba. Rev. Ciênc. Saúde Nova Esperança, v. 12, n. 2, p. 5-13, 2014.

BELOTI, V.; RIBEIRO JÚNIOR, J. C.; TAMANINI, R.; YAMADA, A. K.; CAVALETTI, L.; SHECAIRA, C. L.; NOVAES, D. G.; SILVA, F. F.; GIOMBELLI, C. J.; MANTOVANI, F. D.; SILVA, M. R. Qualidade microbiológica e físico-química do leite cru refrigerado produzido no município de Sapopema/PR. Revista Científica Eletrônica de Medicina Veterinária, v.9, n. 16, 2011.

BERGDOLL, M. S. Staphylococcus aureus. In: Foodborne bacterial pathogens. New York: Marcel Dekker, p.463-523, 1989.

BRASIL, DECRETO-LEI No 923, DE 10 DE OUTUBRO DE 1969. Dispõe sobre a comercialização do leite cru. Diário Oficial da União 1969.

BRASIL, Resolução RDC. n 12, de 02 de janeiro de 2001. Dispõe sobre os princípios gerais para o estabelecimento de critérios e padrões microbiológicos para alimentos. Agência Nacional de Vigilância Sanitária (ANVISA). Disponível em:< http://www. vigilanciasanitaria. gov. br/anvisa. html > Acessado em: 23 de junho de 2017.

BRASIL. Ministério da Agricultura, Pecuária e Abastecimento. Instrução normativa ${ }^{\circ}$ 62, de 29 de dezembro de 2011. Regulamento Técnico de Produção, Identidade e Qualidade do Leite tipo A e Leite Refrigerado. Diário Oficial da União. Brasília, 30 de dezembro de 2011.

BRASIL. Regulamento da inspeção industrial e sanitária de produtos de origem animal. Decreto $\mathrm{n}^{\mathbf{0}} 30.691$, de 29 de 
$\begin{array}{lcccc}\text { março de } & \text { de52. } & \text { Disponível em: } \\ \text { http://www.agricultura.gov.br/assuntos/sustentabilidade/bem- }\end{array}$ estar-animal/arquivos/arquivos-legislacao/decreto-30691-de1952.pdf. Acesso em: 13 de junho de 2017.

CERQUEIRA, M. M. O. P.; PICININ, L. C. A.; SOUSA, M. R.; LEITE, M. O.; PENA, C. F. A. M.; Qualidade da água e impacto na qualidade microbiológica do leite, In: MESQUITA A. J.; DURR, J. W.; COELHO, K. O.; Perspectivas e avanços da qualidade do leite no Brasil. Goiana: Talento, v.1, p. 273-290, 2006.

FREITAS, W. C.; TRAVASSOS, A. E. R.; MACIEL, J. F.; Avaliação microbiológica e físico-química de leite cru e queijo de coalho produzidos no estado da Paraíba. Revista Brasileira de Produtos Agroindustriais, Campina Grande, v.15, n.1, p.35-42, 2013.

GOEL, M.; GOEL, A. Beware your phone is "bugged" mobile phones of dental professionals a potential source of bacterial contamination - A bacteriological study. Indian Journal of Dental Science, v.1, n.1, p. 42-27, 2009.

LAMAITA, H. C.; CERQUEIRA, M. M. O. P.; CARMO, L. S.; SANTOS, D. A.; PENNA, C. F. A. M.; SOUZA, M. R. Contagem de Staphylococcus sp. e detecção de enterotoxinas estafilocócicas e toxina da síndrome do choque tóxico em amostras de leite cru refrigerado. Arq. Bras. Med. Vet. Zootec., v.57, n.5, p.702-709, 2005.

LUZ, D. F.; BICALHO, F. A.; OLIVEIRA, M. V. V.; SIMÕES, A. R. P. Avaliação microbiológica em leite pasteurizado e cru refrigerado de produtores da região do Alto Pantanal sul-mato-grossense. Revista Agrarian, Dourados, v.4, n.14, p.367-374, 2011.

MAREZE, J.; MARIOTO, L. R. M.; GONZAGA, N.; DANIEL, G. C.; TAMANINI, R.; BELOTI, V. Detecção de adulterações do leite pasteurizado por meio de provas oficiais. Semina: Ciências Biológicas e da Saúde, Londrina, v. 36, n. 1, supl, p. 283-290. 2015.

MATTOS, M. R.; BELOTI, V.; TAMANINI, R.; MAGNANI, D. F.; NERO, L. A.; BARROS, M. A. F.; PIRES, E. M. F.; PAQUEREAU, B. P. D. Qualidade do leite cru produzido na região do agreste de Pernambuco, Brasil. Semina: Ciências Agrárias, Londrina, v. 31, n. 1, p. 173-182, 2010 .

MENDES, C. G.; SAKAMOTO, S. M.; SILVA, J. B. A.; JÁCOME, C. G. M.; LEITE, A. I.; Análises físico-químicas e pesquisa de fraude no leite informal comercializado no município de Mossoró, RN. Ci. Anim. Bras., Goiânia, v. 11, n. 2, p. 349-356, 2010.

MENEZES, I. R.; ALMEIDA, A. C.; MORÃO, R. P.; REISS, V.; SANTOS, C. A.; LOPES, I. L. N. Microbiological quality of raw milk produced in northern of Minas Gerais. Rev. bras. ciênc. Vet., v.22, n.1, p. 58-63, 2015.

MORAES, C. R.; FUENTEFRIA, A. M.; ZAFFARI, C. C.; ROCHA, J. P. A. V.; SPANAMBERG, A.; VALENTE, P.; CORÇÃO, G.; COSTA. M. Qualidade microbiológica do leite cru comercializado em cinco municípios no estado do Rio grande do sul, Brasil. Acta Scientiae Veterinariae, v.33 n.3, p.259-264, 2005.
OLIVEIRA, A. B. A.; PAULA, C. M. D.; CAPALONGA, R.; CARDOSO, M. R. I.; TONDO, E. C. Doenças transmitidas por alimentos, principais agentes etiológicos e aspectos gerais: uma revisão. Revista HCPA, v.30, n.3, p.279-285, 2010 .

PINHEIRO, L. A. F. Detecção de fraude no leite com água pela capacidade térmica volumétrica. 2015. 57 fls. Dissertação. (Mestrado Profissional em Ciência e Tecnologia do Leite e Derivados), Universidade Federal de Juiz de Fora, Juíz de fora - MG, 2015.

QUINTANA, R. C.; CARNEIRO, L. C. Avaliação do leite in natura comercializado clandestinamente no município de Morrinhos, GO. Revista do Instituto Adolfo Lutz (Impresso), v. 65, n. 3, p. 194-198, 2006.

RAMIRES, C. H.; BERGER, E. L.; ALMEIDA, R. Influência da qualidade microbiológica da água sobre a qualidade do leite. Archives of Veterinary Science, v.14, n.1, p.36-42, 2009.

SANTOS, A. L.; SANTOS D.O.; FREITAS, C. C.; FERREIRA, B. L. A.; AFONSO, I. F.; RODRIGUES, C. R.; CASTRO, H. C. Staphylococcus aureus: visitando uma cepa de importância hospitalar. Jornal Brasileiro de Patologia e Medicina Laboratorial, v.43, n.6, p. 413-423, 2007.

SEQUETTO, P. L.; ANTUNES, A. S.; NUNES, A. S.; ALCANTARA, L. K. S.; REZENDE, M. A. R.; PINTO, M. A. O. FONTES, G. G.; HÚNGARO, H. M. Avaliação da qualidade microbiológica de leite cru refrigerado obtido de propriedades rurais da zona da mata mineira. Revista Brasileira de Agropecuária Sustentável, v. 7, n. 1, 2017.

SILVA, M. C. D.; SILVA, J. V. L.; RAMOS, A. C. S.; MELO, R. O.; OLIVEIRA, J. O. Caracterização microbiológica e físico-química de leite pasteurizado destinado ao programa do leite no estado de Alagoas. Ciênc. Tecnol. Aliment, Campinas, v.28, n.1, 226-230, 2008.

SILVA, N. da; JUNQUEIRA, V.; SILVEIRA, N. F. A.; TANIWAKI, M. H.; SANTOS, R. F. S. dos, GOMES, R. A. R. Manual de métodos de análise microbiológica de alimentos e água. 4 edição. São Paulo: Livraria Varela, 614p, 2010.

SILVEIRA, M. L. R.; BERTAGNOLLI, S. M. M. Avaliação da qualidade do leite cru comercializado informalmente em feiras livres no município de Santa Maria-RS. Vig Sanit Debate, v. 2, n. 2, p. 75-80, 2014.

VIEIRA, R. P.; JERÔNIMO, M. C.; SANDA, R. T.; ORSINE, J. V. C. Qualidade do leite informal comercializado nas cidades de Ipameri e Orizona - Goiás. Revista Brasileira de Produtos Agroindustriais, Campina Grande, v.16, n.2, p.217-222, 2014.

ZENI, M. P.; MARAN, M. H. S.; SILVA, G. P. R.; CARLI, E. M.; PALEZI, S. C. P. Influência dos microrganismos psicrotróficos sobre a qualidade do leite refrigerado para produção de uht. Unoesc \& Ciência - ACET, v. 4, n. 1, p. 61-70, 2013.

ZOCCHE, F.; BERSOT, L. S.; BARCELLOS, V. C.; PARANHOS, J. K.; ROSA, S. T. M.; RAYMUNDO, N. K. Qualidade microbiológica e físico-química do leite pasteurizado produzido na região oeste do paraná. Archives of Veterinary Science, v.7, n.2, p.59-67, 2002. 